\title{
ANALISA JUMLAH PRODUKSI PADA INDUSTRI RUMAH TANGGA DENGAN MENGGUNAKAN LOGIKA FUZZY: STUDI KASUS UD TEMPE PUJI KECAMATAN BAYANG KABUPATERN PESISIR SELATAN
}

\author{
Ondra Eka Putra, Eka Lia Febrianti \\ Fakultas Ilmu Komputer Universitas Putra Indonesia YPTK Padang \\ Jalan Raya Lubuk Begalung Kota Padang, 25221 \\ Email:kickondra2@gmail.com
}

\begin{abstract}
Total production of a company must be appropriate to the existing demand and supply, if the amount of production is not suitable then it would result in losses of the company because there is no analysis of the market needs for demand and supply of products. UD Tempe Puji is domestic industry that produces tempe every day to provide the needs of the market. In producing UD Tempe Puji only estimate the market needs are uncertain that the market needs are not being met or exceeded. In the analysis of the amount of production at UD Tempe Puji using Tsukamoto fuzzy logic so that the amount of tempe to be produced in accordance with market needs based on demand and supply that exist automatically. Data was analyzed based on the demand, supply and production quantities are never done by UD Tempe Puji. In the method of drawing conclusions fuzzy Tsukamoto, each consequent upon the rule should be represented by a set of fuzzy with the membership function monotonous, as a result, the output results of inference of each rule is given explicitly by $\alpha$-predicate, the final result is obtained by using a weighted average.
\end{abstract}

Key words : Fuzzy Logic, Fuzzy Tsukamoto, Inference System, Weight Average, Rules

\section{PENDAHULUAN}

UD. Tempe Puji merupakan industri rumah tangga yang memproduksi tempe setiap hari menyediakan kebutuhan pasar. Dalam memproduksi UD. Tempe Puji hanya memperkirakan kebutuhan pasar secara tidak pasti sehingga kebutuhan pasar tidak terpenuhi atau berlebih. Tempe mempunyai waktu yang singkat untuk dapat diolah karena jika berlebih maka tempe akan membusuk dan tidak dapat dijual lagi karena tidak dapat diolah oleh konsumen. Dalam analisa jumlah produksi pada UD. Tempe Puji menggunakan metode logika fuzzy (penarikan kesimpulan samar) Tsukamoto sehingga jumlah tempe yang akan diproduksi sesuai dengan kebutuhan pasar berdasarkan permintaan dan persediaan yang ada secara otomatis. Data dianalisa berdasarkan permintaan, persediaan dan jumlah produksi yang pernah dilakukan oleh UD Tempe Puji. Pada metode penarikan kesimpulan samar Tsukamoto, setiap konsekuen pada aturan harus direpresentasikan dengan suatu himpunan samar dengan fungsi keanggotaan yang monoton, sebagai hasilnya, output hasil penarikan kesimpulan (inference) dari tiap-tiap aturan diberikan secara tegas (cnsp) berdasarkan $\alpha$-predikat (fire strength), hasil akhir diperoleh dengan menggunakan rata-rata berbobot (weight average).

Berdasarkan masalah yang ada maka dapat ditarik perumusan masalah sebagai berikut : 
Putra., O. E., \& Febrianti, E. L. 2016. Analisa Jumlah Produksi pada Industri Rumah Tangga dengan Menggunakan Logika Fuzzy: Studi Kasus UD Tempe Puji Kecamatan Bayang Kabupatern Pesisir Selatan.

Journal of Sainstek 8(2): 173-179

1. Bagaimana fuzzy tsukamoto melakukan penarikan kesimpulan berdasarkan rules yang ada?

2. Bagaimana logika fuzzy menganalisa permintaan dan persediaan untuk memprediksi jumlah produksi ?

\section{Metode Fuzzy Tsukamoto}

Metode Tsukamoto merupakan perluasan dari penalaran monoton. Pada metode Tsukamoto, setiap konsekuen pada aturan yang berbentuk IF-THEN harus direpresentasikan dengan suatu himpunan samar dengan fungsi keanggotaan yang monoton. Sebagai hasilnya, output hasil penarikan kesimpulan (inference) dari tiap-tiap aturan diberikan secara tegas (crisp) berdasarkan $\alpha$-predikat (fire strength). Hasil akhir diperoleh dengan menggunakan $r$ ata-rata berbobot (weight average).
Misalkan ada 2 variabel input yaitu $\mathrm{x}$ dan $y$, serta satu variabel output yaitu $z$. variabel $x$ terbagi atas 2 himpunan yaitu A1 dan A2. Variabel y terbagi atas 2 himpunan juga, yaitu $\mathrm{B} 1$ dan $\mathrm{B} 2$ sedangkan variabel output $\mathrm{z}$ terbagi atas 2 himpunan yaitu $\mathrm{C} 1$ dan $\mathrm{C} 2$. Tentu saja himpunan $\mathrm{C} 1$ dan $\mathrm{C} 2$ harus merupakan himpunan yang bersifat yang bersifat monoton. Diberikan 2 aturan sebagai berikut:

IF $\mathrm{x}$ is $\mathrm{A} 1$ and $\mathrm{y}$ is $\mathrm{B} 2$ THEN $\mathrm{z}$ is $\mathrm{C} 1$

IF $\mathrm{x}$ is $\mathrm{A} 2$ and $\mathrm{y}$ is $\mathrm{B} 1$ THEN $\mathrm{z}$ is $\mathrm{C} 2$

$\alpha$-predikat untuk aturan pertama dan kedua, masing-masing adalah $\mathrm{a}_{1}$ dan $\mathrm{a}_{2}$. Dengan menggunakan penalaran monoton, diperoleh dari nilai $\mathrm{z}_{1}$ pada aturan pertama dan $\mathrm{z}_{2}$ pada aturan kedua. Diagram Inference system fuzzy dapat dilihat pada Gambar 1.

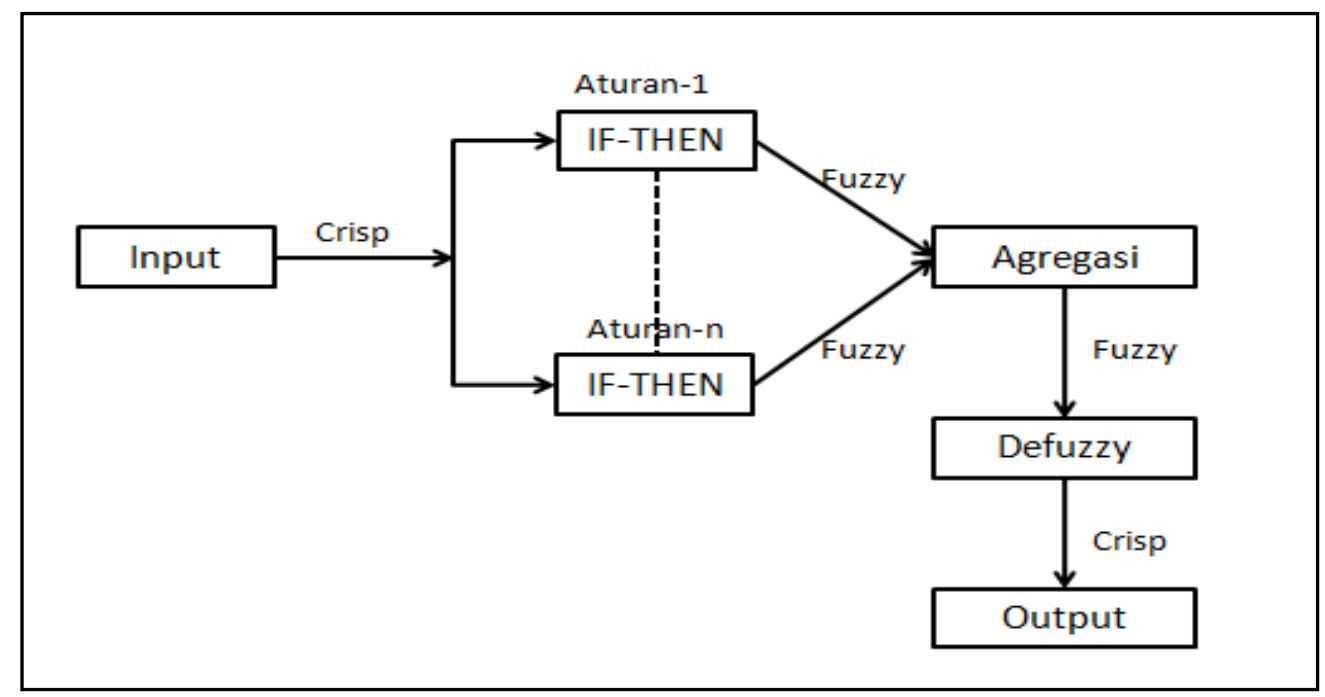

Gambar 1. Diagram Inference System Fuzzy

\section{Konsep Manajemen Operasi}

Secara umum, manajemen operasi diartikan sebagai pengarahan dan pengendalian berbagai kegiatan yang mengolah berbagai jenis sumberdaya untuk membuat barang atau jasa .

Manajemen Operasi tidak mungkin terlepas dari masalah produksi. Produksi (production) adalah seluruh kegiatan yang meliputi pemanfaatan berbagai jumlah dan jenis sumberdaya untuk menghasilkan barang-barang dan/atau jasa-jasa. Namun demikian, dalam memproduksi suatu barang, diperlukan suatu fungsi produksi yang akan memproses barang baku sehingga menjadi suatu produk, 
Putra., O. E., \& Febrianti, E. L. 2016. Analisa Jumlah Produksi pada Industri Rumah Tangga dengan Menggunakan Logika Fuzzy: Studi Kasus UD Tempe Puji Kecamatan Bayang Kabupatern Pesisir Selatan.

Journal of Sainstek 8(2): 173-179

merencanakan produksi dan mengendalikan produksi.

Fungsi Produksi merupakan aktifitas produksi sebagai suatu bagian dari fungsi organisasi perusahaan bertanggungjawab terhadap pengolahan bahan baku menjadi produksi jadi yang dapat dijual. Ada 3 fungsi utama dari kegiatankegiatan produksi yaitu:

1. Proses Produksi, yaitu metode dan teknik yang digunakan dalam mengolah bahan baku menjadi produk.

2. Perencanaan Produksi, merupakan tindakan antisipasi dimasa mendatang sesuai dengan periode waktu yang direncanakan.

3. Pengendalian Produksi, yaitu tindakan yang menjamin bahwa semua kegiatan yang dilaksanakan dalam perencanaan telah dilakukan sesuai dengan target yang telah ditetapkan.

Selain masalah produksi, manajemen operasi juga membahas mengenai permintaan dan persediaan.

Permintaan dibagi menjadi yaitu:

\section{Permintaan Bebas (Independent demand)}

Permintaan bebas adalah permintaan terhadap suatu bahan atau barang yang

sama sekali tidak dipengaruhi oleh atau tidak ada hubungannya dengan

permintaan terhadap bahan atau barang lain.

\section{Permintaan Terikat (Dependent demand)}

Permintaan terikat adalah permintaan terhadap satu jenis bahan atau barang yang dipengaruhi oleh atau bergantung kepada bahan atau barang lain.

\section{Permintaan Terikat Membujur (Vertically dependent demand)}

Permintaan Terikat Membujur terjadi apabila permintaan terhadap suatu barang timbul sebagai akibat adanya permintaan terhadap barang lain, tetapi hanya dalam bentuk pelengkap.

\section{Permintaan Terikat Melintang (Horizontally dependenent demand)}

Permintaan Terikat Melintang terjadi apabila permintaan terhadap suatu barang timbul sebagai akibat adanya permintaan terhadap barang lain, dan merupakan keharusan.
Persediaan didefinisikan sebagai barang yang disimpan untuk digunakan atau dijual pada periode mendatang. Persediaan terjadi apabila jumlah bahan atau barang yang diadakan (dibeli atau dibuat sendiri) lebih besar daripada jumlah yang digunakan (dijual atau diolah sendiri).

Menurut Arman Hakim Nasution dilihat dari jenisnya, persediaan dibedakan menjadi empat, yaitu:

\section{Bahan baku (raw materials)}

Adalah barang-barang yang dibeli dari pemasok (supplier) dan akan digunakan atau diolah menjadi produk jadi yang akan dihasilkan oleh perusahaan.

\section{Bahan setengah jadi (work in process)}

Adalah bahan baku yang sudah diolah atau dirakit menjadi komponen namun masih membutuhkan langkah-langkah lanjutan agar menjadi prouduk jadi.

\section{Barang jadi (finished goods)}

Adalah barang jadi yang telah selesai diproses, siap untuk disimpan di gudang barang jadi, dijual atau didistribusikan ke lokasi-lokasi pemasaran.

\section{Bahan-bahan pembantu (supplies)}

Adalah barang-barang yang dibutuhkan untuk menunjang produksi, namun tidak akan menjadi bagian dari produk akhir yang dihasilkan perusahaan.

\section{Konsep Sistem Pendukung Keputusan (SPK)}

Sistem Pendukung Keputusan (Decission Support System) adalah sistem informasi berbasis komputer yang menyediakan dukungan informasi yang interaktif bagi manajer dan praktisi bisnis selama proses pengambilan keputusan.

SPK dibangun tentunya mempunyai tujuan yang ingin dicapai oleh seorang pembuat keputusan. Menurut Aji Supriyanto Tujuan SPK adalah sebagai "second opinion" atau "information sources" sebagai bahan

pertimbangan seorang manajer sebelum memutuskan kebijakan tertentu.

\section{Komponen SPK}

Menurut Aji Supriyanto SPK dibangun oleh tiga komponen, yaitu:

\section{a. Database}


Putra., O. E., \& Febrianti, E. L. 2016. Analisa Jumlah Produksi pada Industri Rumah Tangga dengan Menggunakan Logika Fuzzy: Studi Kasus UD Tempe Puji Kecamatan Bayang Kabupatern Pesisir Selatan.

Journal of Sainstek 8(2): 173-179

Sistem Database adalah kumpulan semua data yang dimiliki oleh perusahaan baik data dasar maupun transaksi sehari-hari.

b. Model base

Model base adalah suatu model yang merepresentasikan permasalahan

dalam format kuantitatif.

c. Software System

Software System adalah paduan antara database dan model base, setelah sebelumnya direpresentasikan ke dalam bentuk model yang dimengerti oleh sistem komputer.

Sedangkan menurut Tata Sutabri SPK terdiri dari 4 komponen, yaitu:

a. Dialog

Alat untuk berinteraksi antara komputer dengan pemakainya. Pemakai harus bisa mengerti apa arti informasi yang dihasilkan. Ini berarti, sistem (komputer beserta programnya) mudah dipakai (user friendly). Ditinjau dari sudut pemakainya, pemakai harus pula belajar dan berlatih cara penggunaannya serta arti yang dihasilkan.

b. Model

Model serta sistem yang membolehkan pemakai memilih model yang cocok. adalah:

Tiga macam model yang biasa digunakan

1. Optimalisasi: mencari yang terbaik. Contohnya membuat jadwal, membuat perbandingan linear programming, simulasi, dan lain sebagainya.

2. Statistik/matematis: menggambarkan masalah dengan standar kuantifikasi yang ada. Contohnya forecasting, fungsi kemungkinan (probabilitas), proyeksi penjualan, dan lain sebagainya.

3. Financial, mencari kesempatan yang baru yang lebih menguntungkan. Contohnya: investasi, cash flow,

\section{c. Database} manajemen resiko, dan lain sebagainya.

Menurut Indira Rakanita database adalah kumpulan dari item data yang saling berhubungan satu dengan yang lainnya yang diorganisasikan berdasarkan sebuah skema atau struktur tertentu, tersimpan di hardware komputer dan dengan software untuk melakukan manipulasi untuk kegunaan tertentu.

d. Data

Data adalah suatu angka atau kelompok angka yang mempunyai arti atau nilai.

\section{METODE DAN HASIL PENELITIAN}

\section{Mendefenisikan Variabel Fuzzy}

Pada tahap ini, nilai keanggotaan himpunan persediaan dan permintaan saat ini dicari menggunakan fungsi keanggotaan himpunan fuzzy dengan memperhatikan nilai maksimum dan nilai minimum data bulan September 2016. Variabel tersebut antara lain : variable permintaan, variable persediaan, dan variable produksi. Dalam menyelesaikan permasalahan prediksi produksi pada UD. Tempe Puji dengan menggunakan metode Tsukamoto secara manual, ada beberapa langkah yang harus ditempuh.

Ada 3 variabel fuzzy yang akan dimodelkan, yaitu Permintaan, Persediaan, dan Jumlah Produksi.

A. Permintaan

Permintaan terdiri dari 3 himpuan fuzzy yaitu MENURUN, TETAP, dan MENINGKAT. Fungsi keanggotaan himpunan fuzzy MENURUN, TETAP, dan MENINGKAT dari variabel Permintaan Adalah Sebagai Berikut :

$\mu$ PermintaanMENURUN

$=\left\{\begin{array}{cl}\mathbf{1} & \mathrm{x} \leq 700 \\ \frac{1130-\mathrm{x}}{430} & 700 \leq 1130 \\ \mathbf{0} & \mathrm{x} \geq 1130\end{array}\right.$

$\mu$ PermintaanTETAP

$=\left\{\begin{array}{cl}\mathbf{1} & \mathrm{x}-700 \\ 215 & \mathrm{x}=915 \\ \frac{1130-\mathrm{x}}{215} & 915 \leq \mathrm{x} \leq \mathrm{x} \leq 1130 \\ \mathbf{0} & \mathrm{x} \leq 700 \mathrm{~V} \mathrm{x} \geq 1130\end{array}\right.$

$\mu$ PermintaanMENINGKAT 
Putra., O. E., \& Febrianti, E. L. 2016. Analisa Jumlah Produksi pada Industri Rumah Tangga dengan Menggunakan Logika Fuzzy: Studi Kasus UD Tempe Puji Kecamatan Bayang Kabupatern Pesisir Selatan.

Journal of Sainstek 8(2): 173-179

$$
=\left\{\begin{array}{cl}
\mathbf{0} & \mathrm{x} \leq 700 \\
\frac{\mathrm{x}-700}{430} & 700 \leq 1130 \\
\mathbf{1} & \mathrm{x} \geq 1130
\end{array}\right.
$$

$$
\text { Nilai keanggotaan himpunan }
$$

MENURUN, TETAP, dan MENINGKAT dari variabel Permintaan dicari dengan :

$\mu$ PermintaanMENURUN [975]

$=(1130-975) / 430$

$=0,3605$

$\mu$ PermintaanTETAP [975]

$=(1130-975) / 215$

$=0,7209$

$\mu$ PermintaanMENINGKAT [975]

$=(975-700) / 430$

$=0,6395$

B. Jumlah Persediaan

Jumlah Persediaan terdiri dari 3 himpuan

fuzzy yaitu SEDIKIT, SEDANG, dan BANYAK. Fungsi keanggotaan himpunan fuzzy SEDIKIT, SEDANG, dan BANYAK dari variabel Jumlah Produksi Adalah Sebagai Berikut :

$\mu$ PersediaanSEDIKIT

$=\left\{\begin{array}{cl}\mathbf{1} & \mathrm{x} \leq 750 \\ \frac{1100-\mathrm{x}}{350} & 750 \leq 110 \\ \mathbf{0} & 0\end{array}\right.$

$\mu$ PersediaanSEDANG

$$
=\left\{\begin{array}{cl}
\begin{array}{c}
\mathbf{x}-750 \\
175
\end{array} & \mathrm{x}=925 \\
\frac{1100-\mathrm{x}}{175} & 925 \leq \mathrm{x} \leq 925 \\
\mathbf{0} & \mathrm{x} \leq 750 \mathrm{~V} \mathrm{x} \geq 1100
\end{array}\right.
$$

$\mu$ PersediaanBANYAK

$$
=\left\{\begin{array}{cc}
\mathbf{1} & \mathrm{x} \leq 750 \\
\frac{\mathrm{x}-750}{350} & 750 \leq \mathrm{x} \leq 1100 \\
\mathbf{0} & \mathrm{x} \geq 1100
\end{array}\right.
$$

Nilai keanggotaan himpunan SEDIKT, SEDANG, dan BANYAK dari variabel Persediaan dicari dengan : $\mu$ PersediaanSEDIKIT[1000]

$=(1100-1000) / 350$

$=0,2857$ $\mu$ PersediaanSEDANG[1000]

$=(1100-1000) / 175$

$=0,5714$

$\mu$ PersediaanBANYAK[1000]

$=(1000-750) / 350$

$=0,7143$

C. Jumlah Produksi

Jumlah Produksi terdiri dari 3 himpuan fuzzy yaitu MENURUN, TETAP, dan MENINGKAT. FuNgsi keanggotaan himpunan fuzzy MENURUN, TETAP, dan MENINGKAT dari variabel Jumlah Produksi Adalah Sebagai Berikut :

$\mu$ ProduksiMENURUN

$$
=\left\{\begin{array}{cc}
\mathbf{1} & \mathrm{x} \leq 750 \\
\frac{1100-\mathrm{x}}{350} & 750 \leq \mathrm{x} \leq 1100 \\
\mathbf{0} & \mathrm{x} \geq 1100
\end{array}\right.
$$

$\mu$ ProduksiTETAP

$$
=\left\{\begin{array}{cl}
\mathbf{1} & \\
\frac{\mathrm{x}-750}{175} & \mathrm{x}=925 \\
\frac{1100-\mathrm{x}}{175} & 925 \leq \mathrm{x} \leq 925 \\
\mathbf{0} & \mathrm{x} \leq 750 \mathrm{~V} \mathrm{x} \geq 1100
\end{array}\right.
$$

$\mu$ ProduksiMENINGKAT

$$
=\left\{\begin{array}{cc}
\mathbf{0} & \mathrm{x} \leq 750 \\
\frac{\mathrm{x}-750}{350} & 750 \leq \mathrm{x} \leq 1100 \\
\mathbf{1} & \mathrm{x} \geq 1100
\end{array}\right.
$$

\section{Inferensi}

[R1] IF Permintaan MENURUN And Persediaan BANYAK THEN Produksi MENURUN

$$
\begin{aligned}
\alpha 1 & =\min 0,3605 ; 0,7143 \\
& =0,3605
\end{aligned}
$$

Menurut fungsi keanggotaan himpunan Produksi MENURUN dalam aturan fuzzy [R1], maka nilai $\mathrm{Z1}$ adalah :

$$
\begin{aligned}
& =1100-(0,3605 * 350) \\
& =973,825
\end{aligned}
$$


Putra., O. E., \& Febrianti, E. L. 2016. Analisa Jumlah Produksi pada Industri Rumah Tangga dengan Menggunakan Logika Fuzzy: Studi Kasus UD Tempe Puji Kecamatan Bayang Kabupatern Pesisir Selatan.

Journal of Sainstek 8(2): 173-179

[R2] IF Permintaan MENURUN And Persediaan SEDANG THEN Produksi MENURUN

$$
\begin{aligned}
\alpha 2 & =\min 0,3605 ; 0,5714 \\
& =0,3605
\end{aligned}
$$

Menurut fungsi keanggotaan himpunan Produksi MENURUN dalam aturan fuzzy [R2], maka nilai $\mathrm{Z2}$ adalah :

$$
\begin{aligned}
& =1100-(0,3605 * 350) \\
& =973,825
\end{aligned}
$$

[R3] IF Permintaan MENURUN And Persediaan SEDIKIT THEN Produksi MENURUN

$$
\begin{aligned}
\alpha 3 & =\min 0,3605 ; 0,2857 \\
& =0,2857
\end{aligned}
$$

Menurut fungsi keanggotaan himpunan Produksi MENURUN dalam aturan fuzzy [R3], maka nilai $\mathrm{Z3}$ adalah :

$$
\begin{aligned}
& =1100-(0,2857 * 350) \\
& =1000,005
\end{aligned}
$$

[R4] IF Permintaan TETAP And Persediaan BANYAK THEN Produksi MENURUN $\alpha 4=\min 0,7209 ; 0,7143$

$$
=0,7143
$$

Menurut fungsi keanggotaan himpunan

Produksi MENURUN dalam aturan fuzzy [R4], maka nilai $\mathrm{Z4}$ adalah :

$$
\begin{aligned}
& =1100-(0,7143 * 350) \\
& =849,995
\end{aligned}
$$

[R5] IF Permintaaan TETAP And Persediaan SEDANG THEN Produksi TETAP

$$
\alpha 5=\min 0,7209 ; 0,5714
$$$$
=0,5714
$$

Karena Produksi TETAP dalam aturan fuzzy [R5] maka nilai Z5 adalah : $=925$

[R6] IF Permintaan TETAP And Persediaan SEDIKIT THEN Produksi MENINGKAT

$\alpha 6=\min 0,7209 ; 0,2857$

$$
=0,2857
$$

Menurut fungsi keanggotaan himpunan

Produksi MENINGKAT dalam aturan fuzzy

[R6], maka nilai Z6 adalah :

$$
\begin{aligned}
& =(0,2857 * 350)+750 \\
& =848,995
\end{aligned}
$$

[R7] IF Permintaan MENINGKAT And Persediaan BANYAK THEN Produksi MENINGKAT

$$
\begin{aligned}
\alpha 7 & =\min 0,6395 ; 0,7143 \\
& =0,6395
\end{aligned}
$$

Menurut fungsi keanggotaan himpunan Produksi MENINGKAT dalam aturan fuzzy [R7], maka nilai Z7 adalah :

$$
\begin{aligned}
& =(0,6395 * 350)+750 \\
& =973,825
\end{aligned}
$$

[R8] IF Permintaan MENINGKAT And Persediaan SEDANG THEN Produksi MENINGKAT

$$
\begin{aligned}
\alpha 8 & =\min 0,6395 ; 0,5714 \\
& =0,5714
\end{aligned}
$$

Menurut fungsi keanggotaan himpunan Produksi MENINGKAT dalam aturan fuzzy [R8], maka nilai Z8 adalah :

$$
\begin{aligned}
& =(0,5714 * 350)+750 \\
& =949,99
\end{aligned}
$$

[R9] IF Permintaan MENINGKAT And Persediaan SEDIKIT THEN Produksi MENINGKAT

$$
\begin{aligned}
& \alpha 9=\min 0,6395 ; 0,2857 \\
& \quad=0,2857
\end{aligned}
$$

Menurut fungsi keanggotaan himpunan Produksi MENINGKAT dalam aturan fuzzy [R9], maka nilai Z9 adalah :

$$
\begin{aligned}
& =(0,2857 * 350)+750 \\
& =849,995
\end{aligned}
$$

\section{Defuzzyfikasi}

Dalam menentukan output crisp digunakan defuzifikasi rata-rata terpusat pada Fuzzy Tsukamoto yaitu :

$$
\begin{aligned}
\mathrm{Z}= & ((\alpha 1 * \mathrm{Z} 1)+(\alpha 2 * \mathrm{Z} 2)+(\alpha 3 * \mathrm{Z} 3)+ \\
& (\alpha 4 * \mathrm{Z} 4)+(\alpha 5 * \mathrm{Z} 5)+(\alpha 6 * \mathrm{Z} 6)+(\alpha 7 * \mathrm{Z} 7) \\
& +(\alpha 8 * \mathrm{P} 8)+(\alpha 9 * \mathrm{Z} 9)) /(\alpha 1+\alpha 2+\alpha 3+ \\
& \alpha 4+\alpha 5+\alpha 6+\alpha 7+\alpha 8+\alpha 9) \\
= & ((0,3605 * 973,825)+(0,3605 * 973,825) \\
& +(0,2857 * 1000,005)+ \\
& (0,7143 * 849,995)+(0,5714 * 925)+ \\
& (0,2857 * 848,995)+(0,6395 * 973,825)+ \\
& (0,5714 * 949,99)+(0,2857 * 849,995)) / \\
& (0,3605+0,3605+0,2857+0,7143+ \\
& 0,5714+0,2857+0,2857+0,6395+ \\
& 0,5714) \\
\mathrm{Z}= & 850.4785
\end{aligned}
$$


Putra., O. E., \& Febrianti, E. L. 2016. Analisa Jumlah Produksi pada Industri Rumah Tangga dengan Menggunakan Logika Fuzzy: Studi Kasus UD Tempe Puji Kecamatan Bayang Kabupatern Pesisir Selatan.

Journal of Sainstek 8(2): 173-179

\section{Hasil Pengujian Program}

Dibawah ini merupakan hasil pengujian program dengan menggunakan JAVA pada Gambar 2.

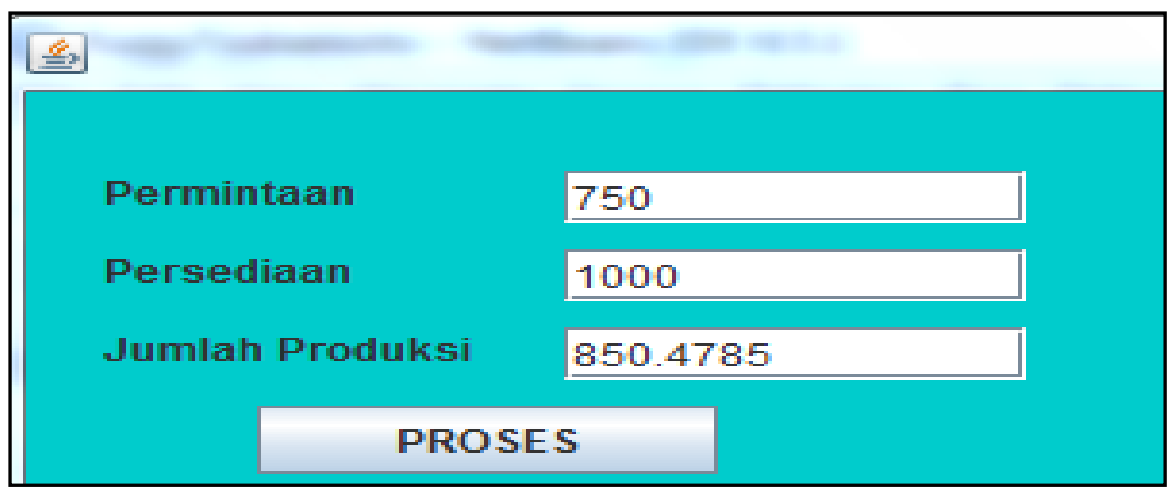

Gambar 2 Hasil Pengujian Fuzzy Tsukamoto Dengan Program

Dari Hasil Pengujian manual dan program maka didapatkan jika permintaan 750 dan Persediaan 1000, maka jumlah produksi yang disarankan adalah 850 (angka pembulatan) untuk memenuhi kebutuhan pasar berarti sistem dengan metode dapat bekerja dengan baik.

\section{KESIMPULAN}

Berdasarkan hasil pengujian secara manual dan program, maka dapat diambil kesimpulan sebagai berikut :

1. Fuzzy Tsukamoto dapat dijadikan sebagai solusi yang baik untuk memprediksi jumlah produksi pada UD Tempe Puji karena dapat beroperasi dengan cepat.

2. Tingkat kecepatan dan ketepatan pada sistem yang menggunakan metode Tsukamoto sudah baik dengan adanya penginputan data permintaan dan persediaan yang mudah dimengerti serta penampilan hasil yang cukup cepat dapat langsung diketahui oleh admin ataupun user.

\section{DAFTAR KEPUSTAKAAN}

J Ross, Timothy. 2010. Fuzzy Logic With Enggineering Application. United Kingdom : Wiley.

Kusrini S.Kom. 2014. Konsep dan Aplikasi Sistem Pendukung Keputusan. 2014. Yogyakarta : Andi.

Kusumadewi, Sri, \& Hartati, Sri. 2010. NeuroFuzzy : Integrasi Sistem Fuzzy \& Jaringan Saraf. Yogyakarta : Graha Ilmu

Kusumadewi, Sri and Purnomo, Hari. 2010. Aplikasi Logika Fuzzy Untuk Pendukung Keputusan. Yogyakarta: Graha Ilmu.

Sutujo, T., Mulyanto, Edi., Suhartono, Vincent., \& Rini, Benedicta. 2011. Kecerdasan Buatan. Semarang : Andi

Suyanto. 2011. Artificial Intelligence : Searching, Reasoning, Planning, dan Learning. Bandung : Informatika

Zhi, Zhong. 2011. Advanced Artificial Intellegence. London : World Scientific 